\title{
Relationships between lumbar inter- vertebral motion and lordosis in healthy adult males: a cross sectional cohort study
}

Alister du Rose ${ }^{1,2^{*}}$ and Alan Breen ${ }^{1,2}$

\begin{abstract}
Background: Intervertebral motion impairment is widely thought to be related to chronic back disability, however, the movements of inter-vertebral pairs are not independent of each other and motion may also be related to morphology. Furthermore, maximum intervertebral range of motion (IV-RoMmax) is difficult to measure accurately in living subjects. The purpose of this study was to explore possible relationships between (IV-RoMmax) and lordosis, initial attainment rate and IV-RoMmax at other levels during weight-bearing flexion using quantitative fluoroscopy (QF).

Methods: Continuous QF motion sequences were recorded during controlled active sagittal flexion of $60^{\circ}$ in 18 males (mean age 27.6 SD 4.4) with no history of low back pain in the previous year. IV-RoMmax, lordotic angle, and initial attainment rate at all inter-vertebral levels from L2-S1 were extracted. Relationships between IV-RoMmax and the other variables were explored using correlation coefficients, and simple linear regression was used to determine the effects of any significant relationships. Within and between observer repeatability of IV-RoMmax and initial attainment rate measurements were assessed in a sub-set of ten participants, using the intra-class correlation coefficient (ICC) and standard error of measurement (SEM).
\end{abstract}

Results: QF measurements were highly repeatable, the lowest ICC for IV-RoMmax, being 0.94 (0.80-0.99) and highest SEM $\left(0.76^{\circ}\right)$. For initial attainment rate the lowest ICC was $0.84(0.49-0.96)$ and the highest SEM (0.036). The results also demonstrated significant positive and negative correlations between IV-RoMmax and IV-RoMmax at other lumbar levels $(r=-0.64-0.65)$, lordosis $(r=-0.52-0.54)$, and initial attainment rate $(r=-0.64-0.73)$. Simple linear regression analysis of all significant relationships showed that these predict between 28 and $42 \%$ of the variance in IV-RoMmax.

Conclusions: This study found weak to moderate effects of individual kinematic variables and lumbar lordosis on IV-RoMmax at other intervertebral levels. These effects, when combined, may be important when such levels are being considered by healthcare professionals as potential sources of pain generation. Multivariate investigations in larger samples are warranted.

Keywords: Spine kinematics, Fluoroscopy, Lordosis, Reliability, Agreement

\section{Background}

Movement of the lumbar spine requires the participation of multiple segments and the relevant contributions of segments are a function of their own mechanical properties [1]. Aberrant spinal movement patterns are widely thought to be related to musculoskeletal pain and

\footnotetext{
* Correspondence: adurose@aecc.ac.uk

'Institute for Musculoskeletal Research and Clinical Implementation,

Anglo-European College of Chiropractic, Parkwood Road, Bournemouth BH5 2DF, UK

${ }^{2}$ Faculty of Science and Technology, Bournemouth University, Fern Barrow, Poole BH12 5BB, UK
}

dysfunction [2-4], and as such they are used to inform surgical and conservative clinical decision making [1,5-7], and as indicators of spinal stability [3, 8-10]. As a consequence of their wide variation in both low back pain and healthy populations however, the clinical importance of factors such as inter-vertebral range of motion (IV-RoM) remains unclear, and the identification of biomechanical factors that may contribute to low back pain, remains a challenge [11]. Information about how IV-RoM may interact with other biomechanical factors may therefore help provide a better understanding of how variations in lumbar 
inter-vertebral kinematics may affect prognosis and treatment outcomes.

The starting point for this should be the collection of detailed normative quantitative data with respect to in vivo inter-vertebral motion and morphologic parameters [12]. Quantitative fluoroscopy (QF) has been shown to be an accurate and reliable 2D method of doing this [11, 13, 14]. Recent technological advances have enabled the acquisition of 3D lumbar kinematic data in vivo [15], however it has been demonstrated that there is only minimal axial rotation and lateral bending associated with movements in the sagittal plane [16-19], and in terms of QF inter-vertebral measurements, out of plane motion of up to $10^{\circ}$ does not significantly affect accuracy [20]. Therefore, the greater expense and dose associated with current $3 \mathrm{D}$ techniques against the clinical and research benefits, perhaps justify the use of 2D QF technology, particularly in the sagittal plane. Indeed, the investigation of spinal mechanical behaviour has been outlined as a priority for future QF research [21], which begins with the relationships between IV-RoM and other kinematic variables in healthy, pain-free control populations. Such normative information should provide insights into the possible biomechanical consequences of changes within each.

Previous dynamic studies using fluoroscopy have highlighted contrasting ranges and patterns of angular rotation between the upper and lower lumbar motion segments [12, 22-24], which make different contributions to movements such as sagittal flexion. There is also evidence to suggest that lordosis may relate to an individual's spinal flexibility [25]. Indeed, a recent MRI study that investigated the intrinsic shape of the lumbar spine concluded that lumbar spinal shapes may be related to an individual's risk of injury [26].

IV-RoM is the most common measure of inter-vertebral motion [11, 13, 27] and attainment rate (defined as the velocity with which IV-RoM is reached), has been identified as a reflection of intervertebral restraint [11, 28, 29]. Initial attainment rate is a refinement of this which measures the slackness of an inter-vertebral motion segment in its initial phase of rotation [30,31]. This parameter has been shown to correlate with the dynamic neutral zone [32], and is therefore also believed to be of importance when considering the stability of motion segments.

Relationships between these and other kinematic and morphologic variables have not been previously explored. This study examined the relationships between IVRoMmax at lumbar inter-vertebral levels from L2 to S1 and lordosis, initial attainment rate and IV-RoMmax at other lumbar spine levels during forward bending in healthy controls. It also assessed the intra and interobserver repeatability of the QF measurement of IVRoMmax and initial attainment rate.

\section{Methods}

\section{Study design}

This was a cross-sectional, laboratory based cohort study of the relationships between L2-S1 IV-RoMmax and lordosis, initial attainment rate and IV-RoMmax at other levels.

\section{Participants}

The eligibility criteria for the study are shown in Table 1. Twenty male participants were recruited from the AngloEuropean College of Chiropractic (AECC) student population over a 5 month period between May and September 2014. National Research ethics Service (NRES) approval was acquired (Bristol 10/H0106/65) and prior to the collection of data, written informed consent was obtained from each participant. A participant number of 20 was selected, as a sample size $\geq 12$ has been recommended as sufficient for the precision around the measurement to be used in an exploratory study [33].

\section{Data collection and processing}

All data collection was conducted at the radiology department of the AECC. Fluoroscopic images of the lumbar spine were collected at $15 \mathrm{~Hz}$ using a Siemens Arcadis Avantic VC10A digital fluoroscope (CE0123) and a motion frame which acted to both stabilise the participants and guide their bending motion. Participants were asked to stand in a neutral upright position with their right side against the motion frame (Fig. 1a), and shadow a rotating arm rest which guided them during continuous fluoroscopic imaging, through a standardised range of $60^{\circ}$ of forward flexion and return to upright, over a period of approximately $20 \mathrm{~s}$. A review of spinal ranges of motion in controls proposed that the lumbar spine has an overall range (inclusive of both flexion and extension components) of approximately $80^{\circ}$, with $60^{\circ}$ of this attributable to the flexion component [34]. It was therefore theorised that the majority of each participant's lumbar inter-vertebral movement would be captured within this range.

Prior to image acquisition, participants were taken in $20^{\circ}$ stages through to the full $60^{\circ}$ to safeguard that they were able to tolerate the movement. The movement of the motion frame was recorded by electronic feedback from its motor drive, and synchronised with the fluoroscopic imaging. To minimise bending from the hip joints, the pelvis was stabilised using a strap secured around the anterior superior iliac spine bilaterally, and attached to an appendage of the motion frame directly posterior to the participant (Fig. 1b).

A lead apron was worn to shield the gonads, and participants were verbally reminded to maintain a neutral bending position during the flexion cycle. The position of the central ray was targeted at L4 to make sure 
Table 1 Eligibility criteria

\begin{tabular}{ll}
\hline Inclusion & Exclusion \\
\hline Males aged 20-40 years & $\begin{array}{l}\text { Inadequate understanding of } \\
\text { English }\end{array}$ \\
$\begin{array}{l}\text { An ability to understand written } \\
\text { information }\end{array}$ & $\begin{array}{l}\text { Currently receiving treatment for } \\
\text { osteoporosis }\end{array}$ \\
Willing to participate and able & A history of recent abdominal or \\
to give informed consent & pelvic surgery \\
Consent to General Practitioner & A history of previous lumbar \\
being informed & spine surgery \\
A BMI of <30 & A BMl of >30 \\
No history of low back pain & Any medical radiation exposure \\
that prevented normal activity & in the past year or exposure in \\
for at least 1 day in the & the past 2 years with a dose \\
previous year & greater than 8 mSv \\
& Involvement in any other ongoing \\
& research study
\end{tabular}

that all vertebrae (L2-S1) were included in the image field Fig. 2.

The fluoroscopic sequences were then transferred to a desk top computer for analysis using bespoke image processing codes written in Matlab (The Mathworks, Cambridge). Using the screen cursor, the outlines of each vertebra from L2-S1 in the first image of each sequence were marked-up manually with an electronic template. In order to increase precision, this process was replicated five times for each sequence and the results were averaged. In all subsequent image frames the bespoke software tracked each vertebra automatically, creating a continuous measurement of its movement throughout the flexion and return bending sequence. To ensure that template tracking was maintained throughout the sequence, visual checks were made using video playback.

The data collected comprised of range of motion (IV-RoM), initial attainment rate, and lordosis and the reliability and agreement of the first two of these were assessed as part of the study [35]. The technique used to measure changes in inter-vertebral angle is discussed in detail elsewhere [36], and is shown in Fig. 3.

IV-RoMmax for each inter-vertebral level (L2-S1) was calculated as the maximum angular range reached at any point throughout the $60^{\circ}$ flexion and return cycle (Fig. 4). Initial attainment rate for each level was calculated as the ratio of the slopes of motion frame movement and the inter-vertebral rotation over the first $10^{\circ}$ immediately following the onset of intervertebral motion. The calculation of this variable has been outlined in detail elsewhere [31], and is also shown in Fig. 5. Lordosis was measured as the sum of all inter-vertebral angles (L2-S1), from the first image in the sequence. All participant data were anonymised.
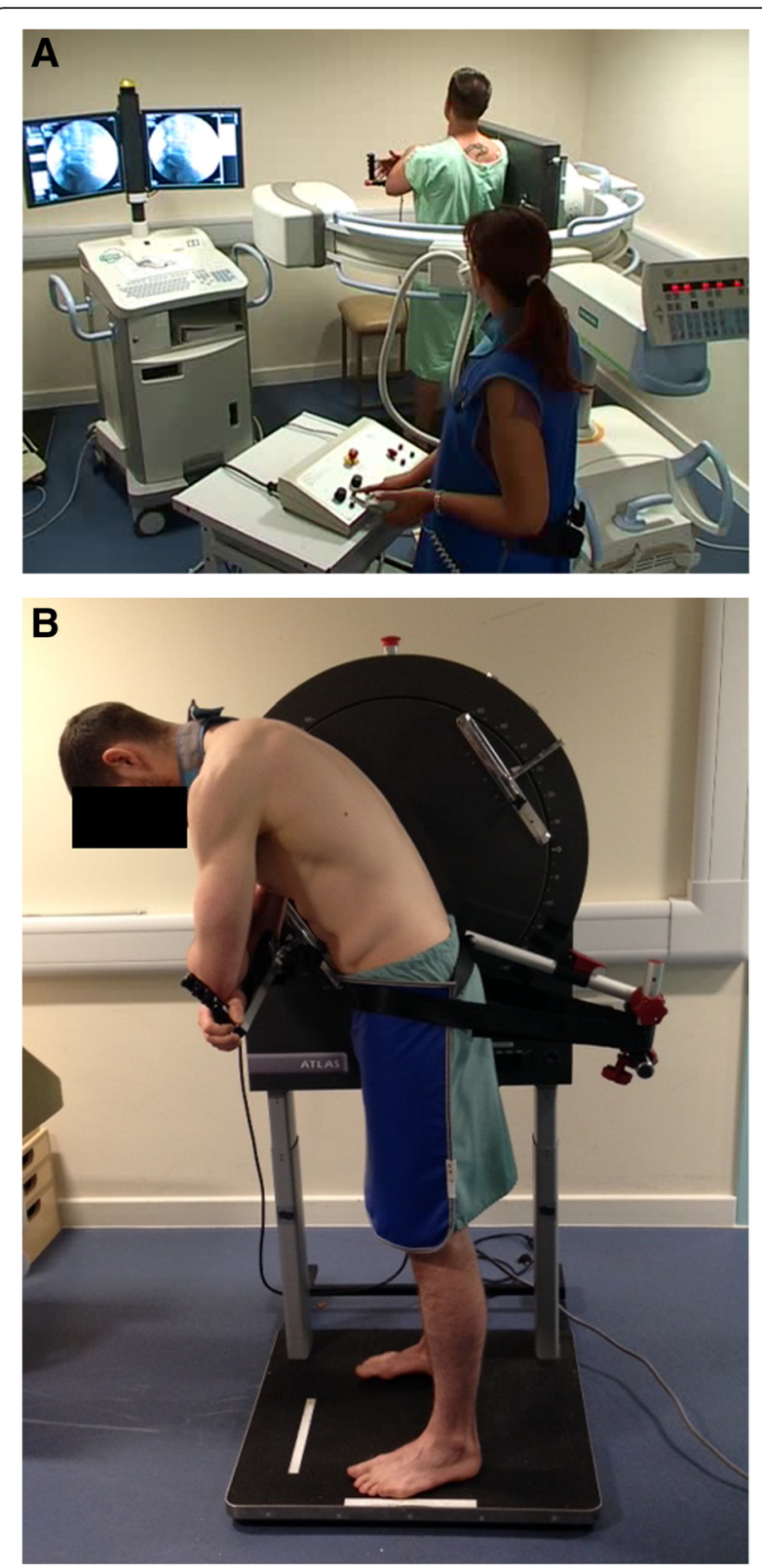

Fig. 1 a Fluoroscope and weight-bearing motion frame. b Weightbearing motion frame during flexion including pelvic restraint and lead protection

\section{Reliability and agreement}

A convenience sample of ten participants was used for the intra- and inter-observer repeatability studies. The intra-observer study was conducted, with a 6 week separation between image mark-ups. The inter-observer study images were processed by two independent observers. The first observer (template marker) was a medical physicist, and the second was ADR. The observers were blinded to the others' results, and had 3 and 1 year(s) experience of template marking respectively. 


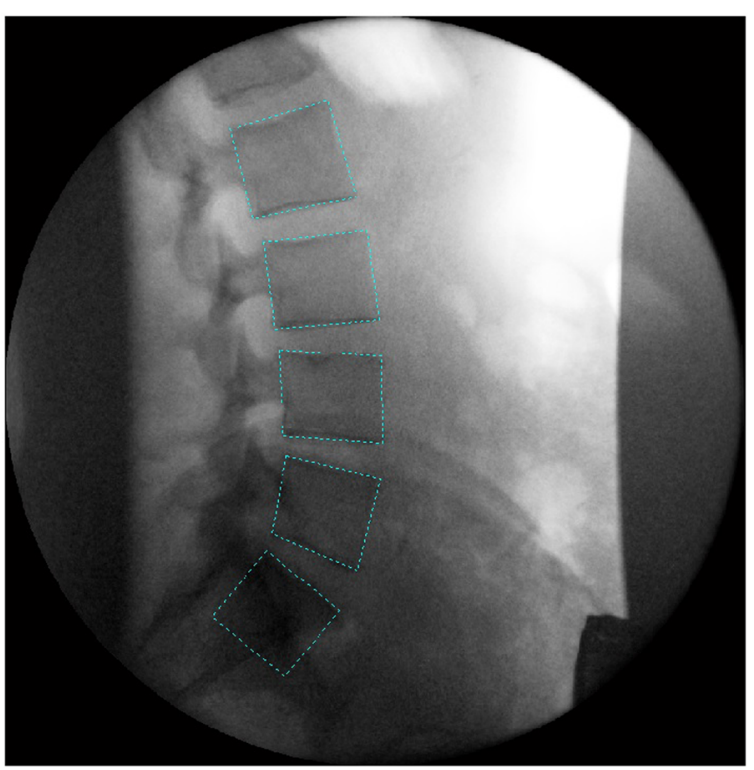

Fig. 2 Fluoroscopic image of the lumbar spine. Templates placed around the lumbar vertebrae (L2-S1) on the first frame of the QF sequence

\section{Data analysis}

The normality of all data were tested using the Shapiro-Wilk test. Relationships between IV-RoMmax and other biomechanical variables, from normally distributed data were analysed using the Pearson productmoment correlation coefficient, and non-normal data using the Spearman's Rank Correlation. Any significant relationships $(p$ values $<0.05)$ were also analysed using simple linear regression. Intra- and inter-observer reliability and agreement of both IV-RoMmax and initial attainment rate measurements, were assessed using intra-class correlations (ICC 3, 1), and the standard error of measurement (SEM) respectively. Statistical analysis was performed using IBM SPSS (version 21).

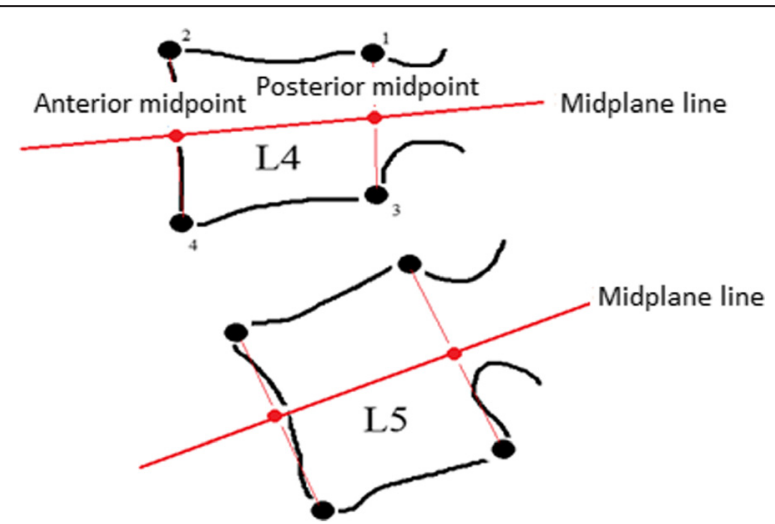

Fig. 3 Frobin method to measure the change in inter-vertebral angle. Rotation is calculated as the angle between the two midplane lines
Note: This study conformed to the STROBE checklist for reports of observational studies [37] (Additional file 1).

\section{Results}

Twenty males satisfying the eligibility criteria consented to participate. Template tracking failure occurred in two participant's sequences, and their data were removed. The mean (SD) age, height, and body mass Index (BMI) were 27.6 years (4.4), $1.8 \mathrm{~m}$ (0.06), and 24 (2.2) respectively. The average radiographic exposure factors for the group were documented as $79.7 \mathrm{kV} \mathrm{SD} \mathrm{(5.4)} \mathrm{and} \mathrm{55.4} \mathrm{mA} \mathrm{SD}$ (3.4). ICRP103 conversion software PCXMC (Monte Carlo Simulation Package) was used to calculate the mean effective dose as $0.143 \mathrm{mSv}$.

\section{Reliability and agreement IV-RoMmax}

The ICC's (reliability) and SEM's (agreement) for both intra- and inter-observer IV-RoMmax studies are shown in Table 2. The results suggest excellent reliability with the smallest ICC being 0.96 (95\% CI 0.82-0.99) and 0.94 (95\% CI 0.80-0.99) for the intra- and interobserver studies respectively. When comparing intraand inter-observer repeatability, it was expected that intra-observer comparisons would demonstrate better reliability and agreement $[11,14]$. This trend was not observed in these weight-bearing samples however, and ICC's were the same or slightly better in the interobserver group for two out of the four inter-vertebral levels. Agreement was found to be better than $1^{\circ}$ at all levels, for both intra- and inter-observer studies.

\section{Initial attainment rate}

The ICC's (reliability) and SEM's (agreement) for both intra- and inter-observer weight-bearing initial attainment rate studies are also shown in Table 2 . The reliability of initial attainment rate measurements was also acceptable, being more than 0.81 [38] in both intra- and inter-observer studies at all inter-vertebral levels. The smallest ICC was 0.84 (95\% CI 0.49-0.96) at the level of L3-L4 in the inter-observer study, and the largest was 0.98 (95\% CI 0.92-1.0) in the intra-observer study at the same level. The intra-observer study demonstrated consistently better reliability (including narrower confidence intervals) than that of the inter-observer study. The agreement of initial attainment rate measurements is also acceptable in both intra- and inter-observer studies. In the upper inter-vertebral levels (L2-3 and L3-4) SEM's are comparatively lower in the intra-observer study, however in the lower levels (L4-L5 and L5-S1) SEM's are comparatively higher. 


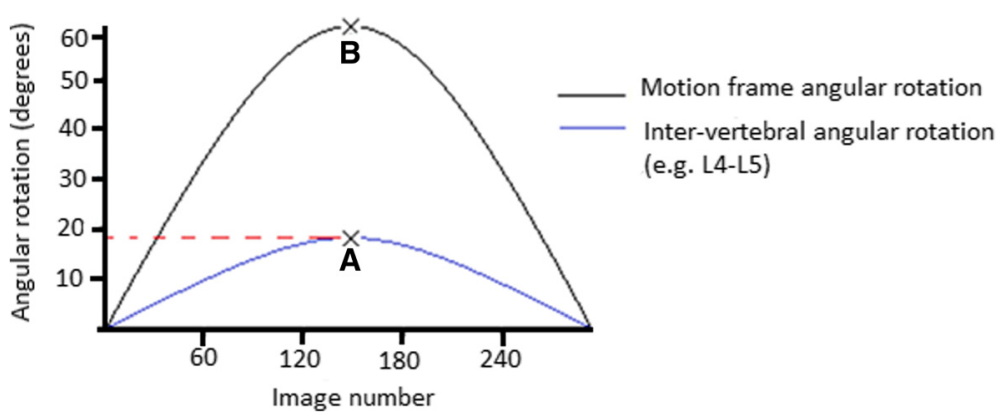

Fig. 4 Calculation of the maximum angular range reached during flexion (IV-RoMmax). Maximum angle of rotation reached by each inter-vertebral motion pair (A); Maximum motion frame rotation (B) (always $60^{\circ}$ during the QF sagittal flexion examination). Note: Maximum inter-vertebral range of motion may not always be found at the end of motion frame movement range

\section{Correlations}

A summary of the correlations between all biomechanical variables and IV-RoMmax is given in Table 3. Significant correlations were found between IV-RoMmax and at least one other variable at all inter-vertebral levels. These were consistently of mid-level strength ( $\mathrm{r}$ - values ranging from -0.64 to 0.73 ). Lordosis was positively correlated with IV-RoMmax at L2-L3 and negatively with L4-5 ( $r=0.54$ and -0.52 respectively). In terms of IVRoMmax versus IV-RoMmax at other levels, correlations were found between all levels except L5-S1. L2-L3 range was shown to be positively correlated with that of L3-4, but negatively correlated with L4-5. The strongest relationship was found between initial attainment rate at L3-4 and L5-S1 IV-RoMmax $(r=0.73)$. Indeed, initial attainment rate showed examples of strong correlations with range at all levels.

\section{Simple linear regression analysis}

The coefficients of determination $\left(\mathrm{r}^{2}\right)$ for each of the significant correlations are shown in Fig. $6(\mathrm{a}-\mathrm{h})$. The values range from $(0.28$ to 0.42$)$ and demonstrate that IV-RoMmax, can be influenced by lordosis, the IVRoMmax at other lumbar levels, and initial attainment rate. Figure 6a for example shows that $41 \%$ of the variability in L4-L5 IV-RoMmax can be accounted for by the range of L2-L3 IV-RoMmax.

\section{Discussion \\ Agreement and reliability}

The agreement and reliability of IV-RoM and initial attainment rate measurements using continuous QF image data has previously been assessed in recumbent participants [11]. As anticipated, the reliability and agreement of IVRoM measurements during recumbent sagittal flexion were found to be similar to those found in the current work, with 'substantial' reliability [38], and acceptable error (i.e. $<1^{\circ}$ ) demonstrated at all levels for both intra- and inter-observer studies. It has been demonstrated that reliability and agreement are typically decreased in the interobserver group [11, 14], however these differences were shown to be minimal in the current study, and there were notable exceptions to the trend (Table 2). Although ICC's were very similar between intra- and inter-observer groups, generally the width of the CI's and the SEM's were larger in the latter. It appears that whilst errors arising from the use of different observers did have a small impact, interobserver agreement and reliability is still acceptable.

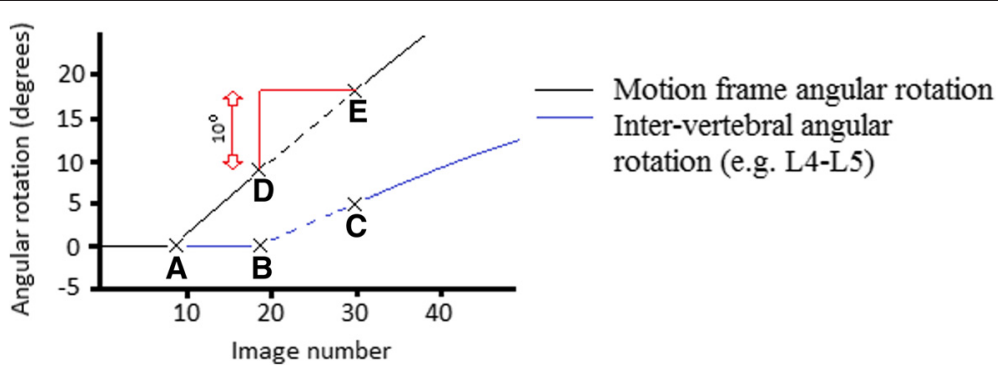

Fig. 5 Calculation of initial attainment rate. The dotted lines represent the lines of best fit for motion frame movement (black) and inter-vertebral motion (blue), from which gradients can be calculated. Point at which the motion frame begins movement (A); Point at which inter-vertebral motion begins (B); Dotted line between $(B)$ and $(C)=$ the area under the curve from which the line of best fit is drawn to calculate inter-vertebral movement gradient; Dotted line between $(D)$ and $(E)=$ the area of the curve from which the line of best fit is drawn to calculate the motion frame movement gradient. Initial attainment rate is the calculated as the slope of $\mathrm{BC} /$ slope of $\mathrm{DE}$ 
Table 2 Intra- and inter-observer reliability and agreement of IV-RoMmax and initial attainment rate measurements during weightbearing flexion and return $n=10$

\begin{tabular}{|c|c|c|c|c|}
\hline Inter-vertebral level & Intra-observer ICC (95 \% Cl) & Inter-observer ICC (95 \% CI) & Intra-observer SEM $\left(^{\circ}\right)$ & Inter-observer SEM $\left(^{\circ}\right)$ \\
\hline \multicolumn{5}{|l|}{ IV-RoMmax } \\
\hline L2-L3 & $0.98(0.92-1.0)$ & $0.94(0.80-0.99)$ & 0.45 & 0.76 \\
\hline L3-L4 & $0.99(0.96-1.0)$ & $0.99(0.67-1.0)$ & 0.23 & 0.24 \\
\hline L4-L5 & $0.99(0.97-1.0)$ & $0.98(0.93-1.0)$ & 0.39 & 0.59 \\
\hline L5-S1 & $0.96(0.82-0.99)$ & $0.99(0.94-1.0)$ & 0.54 & 0.61 \\
\hline Inter-vertebral level & Intra-observer ICC (95 \% Cl) & Inter-observer ICC (95 \% CI) & Intra-observer SEM ratio & Inter-observer $\mathrm{SEM}_{\text {ratio }}$ \\
\hline \multicolumn{5}{|l|}{ Initial attainment rate } \\
\hline L2-L3 & $0.95(0.78-0.99)$ & $0.95(0.80-0.99)$ & 0.026 & 0.036 \\
\hline L3-L4 & $0.98(0.92-1.0)$ & $0.84(0.49-0.96)$ & 0.02 & 0.033 \\
\hline L4-L5 & $0.92(0.71-0.98)$ & $0.91(0.70-0.98)$ & 0.032 & 0.018 \\
\hline L5-S1 & $0.95(0.81-0.99)$ & $0.88(0.53-0.97)$ & 0.023 & 0.019 \\
\hline
\end{tabular}

It was anticipated that there might be a marginal decrease in the repeatability of measurements at intervertebral levels closer to the edge of the image field (i.e. L2-3 and L5-S1). This predicted difficulty (due to superimposition of the ilia) in template marking/tracking of L5-S1 was the reason cited by Mellor et al. [11] for its exclusion, and it makes sense that tracking problems could be more likely to occur in templates that may partially leave the image field i.e. L2-3 and L5-S1. The current study's results have shown however, that reliability and agreement of QF IV-RoMmax measurements at all levels, including L2-L3 and L5-S1, can be achieved in a weight-bearing protocol, at an acceptable level.

The initial attainment rate measurements were also highly repeatable; there was however a clearer distinction between the confidence intervals of intra- and interobserver groups, being notably wider in the latter at L3-4 and L5-S1 levels (Table 2). These may be best explained by differences in the experience levels of the observers [14]. Differences in marking experience may also be the reason for the relatively increased measurement error in the inter-observer group at upper inter-vertebral levels, and improved agreement at the lower levels.

\section{Correlations}

The results showed evidence of relationships between kinematic variables at multiple levels of the lumbar spine. IV-RoMmax at all inter-vertebral levels was significantly correlated, positively or negatively, with at least one other kinematic or morphological variable, and there appear to be trends in these relationships in terms of the regions of the lumbar spine. Previous studies have demonstrated that during sagittal flexion, upper lumbar segments typically move first [24], and have the greatest ranges of motion [39]. In this study, L2-3 and L3-4 were strongly positively correlated, suggesting that they tend to work in tandem. However, they were also both negatively correlated with the IV-RoMmax of L4-5 and its initial attainment rate. This suggests a compensatory function between them, and if it is assumed that instability results from reduced restraint, then it may be suggested that reduced motion at

Table 3 Correlations between kinematic variables and IV-RoMmax at all inter-vertebral levels $n=18$ (Significant relationships are highlighted in bold)

\begin{tabular}{|c|c|c|c|c|c|c|c|c|}
\hline \multirow[t]{2}{*}{ Kinematic variable } & \multicolumn{2}{|c|}{ L2-L3 IV-RoMmax } & \multicolumn{2}{|c|}{ L3-L4 IV-RoMmax } & \multicolumn{2}{|c|}{ L4-L5 IV-RoMmax } & \multicolumn{2}{|c|}{ L5-S1 IV-RoMmax } \\
\hline & $r$ & $\mathrm{p}$ & $r$ & $\mathrm{p}$ & r & $\mathrm{p}$ & r & p \\
\hline Lordosis & 0.54 & 0.021 & 0.401 & 0.099 & -0.52 & 0.026 & -0.02 & 0.973 \\
\hline L2-L3 IV-RoMmax & - & & 0.65 & 0.003 & -0.64 & 0.004 & -0.35 & 0.157 \\
\hline L3-L4 IV-RoMmax & 0.65 & 0.003 & - & & -0.29 & 0.234 & -0.12 & 0.636 \\
\hline L4-L5 IV-RoMmax & -0.64 & 0.004 & -0.29 & 0.234 & - & & 0.15 & 0.558 \\
\hline L5-S1 IV-RoMmax & -0.35 & 0.157 & -0.12 & 0.636 & 0.15 & 0.558 & - & \\
\hline L2-L3 Initial attainment rate & 0.20 & 0.419 & 0.14 & 0.58 & -0.09 & 0.713 & 0.21 & 0.403 \\
\hline L3-L4 Initial attainment rate & -0.18 & 0.465 & -0.11 & 0.668 & 0.17 & 0.512 & 0.73 & 0.001 \\
\hline L4-L5 Initial attainment rate & -0.53 & 0.023 & -0.64 & 0.004 & 0.59 & 0.009 & 0.02 & 0.949 \\
\hline L5-S1 Initial attainment rate & 0.05 & 0.852 & -0.02 & 0.938 & 0.07 & 0.776 & 0.42 & 0.079 \\
\hline
\end{tabular}


A

$n=18, r^{2}=0.41, Y=17.99+-0.92 X, p=0.004$

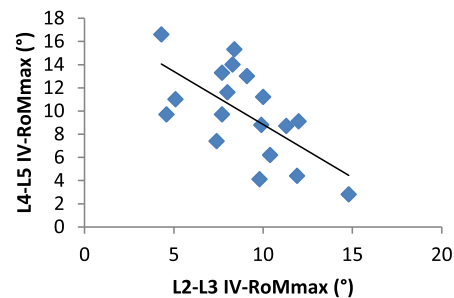

C

$n=18, r^{2}=0.29, Y=0.32+0.17 X, p=0.021$

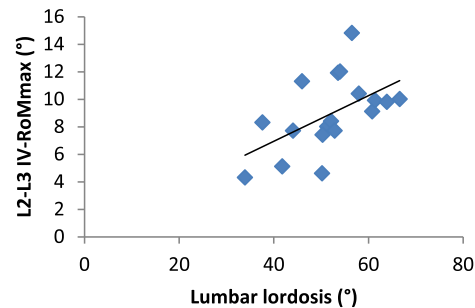

E
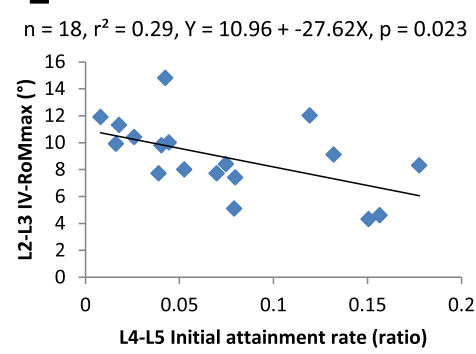

G

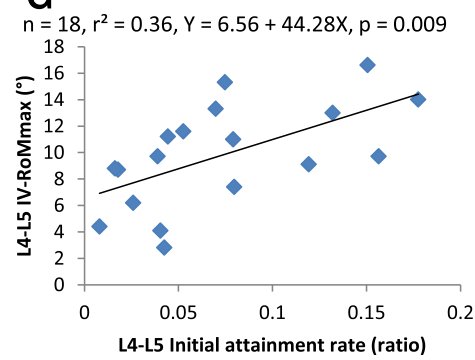

B

$n=18, r^{2}=0.42, Y=6.78+0.39 X, p=0.003$

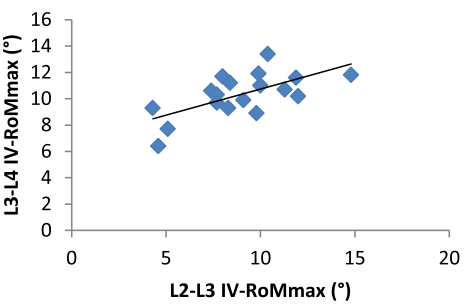

D

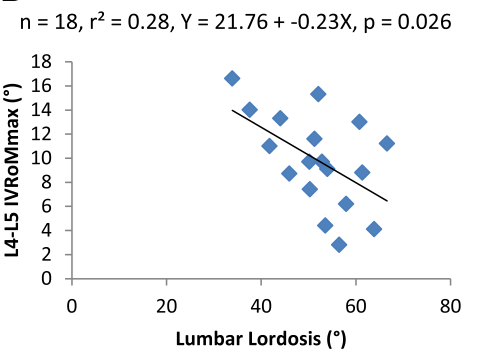

$\mathbf{F}$

$n=18, r^{2}=0.41, Y=11.79+-20.1 X, p=0.004$

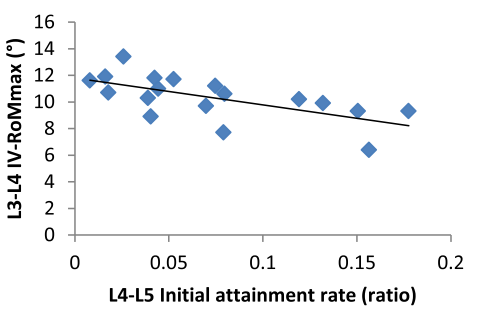

H

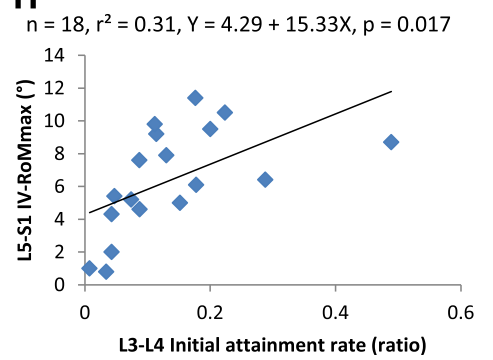

Fig. 6 Scatter plots and linear regression values for all significant correlations. Significant relationships between IV-RoMmax and IV-RoMmax at other levels ( $\mathbf{a}$ and $\mathbf{b}$ ), lordosis (c and $\mathbf{d}$ ), and initial attainment rate (e-h). $n=$ sample size, $r^{2}=$ coefficient of determination, $Y=$ linear regression equation, $p=p$ value for the regression coefficient

these upper levels could feasibly be a factor in promoting L4-5 instability as a consequence of motion stress transfer.

Relationships with IV-RoMmax were different for the lower lumbar segments. While the ranges of L2-3 and L4-5 were inversely correlated, lordosis was positively associated with L2-3 range and negatively with L4-L5 range, while initial attainment rate at L4-5 was positively correlated with L4-L5 range, but negatively with the range of L2-3. This supports the view that a degree of lordosis may allow a more even sharing of motion throughout the lumbar spine, offering a degree of protection to the L4-5 segment during bending [26], and that lordosis itself has an important role in spinal biomechanical behaviour [40]. Together, these may have implications for prognosis in patients with L4-5 pain generation, a segment commonly involved in lumbar degeneration [22], especially if there is both hypo-lordosis and motion restriction in the upper lumbar spine.

Several relationships approached significance and may therefore also be important. L5-S1 and L4-5 IV-RoMmax and their initial attainment rates were positively correlated. However, this was not true for the upper segments. Increased range and initial attainment rate at L4-5 were both correlated to stiffness at L2-3 and added to by a 
reduction in lumbar lordosis, which has implications for proposed surgical stabilisation of upper levels. Conversely, while attainment rate and IV-RoMmax at L4-5 were positively correlated, L4-5 attainment rate was negatively correlated with the IV-RoMmax at L2-3 and with L3-4 above. As both attainment rate and IV-RoMmax are expressions of intervertebral restraint, these relationships may be regarded as compensatory, contributing to the attenuation of stress throughout the lumbar spine linkages. Thus there are indications of interactions and effects between kinematic and morphological variables at different levels.

Finally, there is an increasing awareness of the importance of sagittal parameters when planning surgical strategy [41, 42], correcting sagittal balance, or when considering more conservative treatment options. The ability to accurately assess and measure sagittal kinematic and morphological values may be important, as we attempt to understand their potential clinical utility [43]. The existence of intrinsic links between morphological variables such as lordosis have been described before [44], however we are the first to use continuous in vivo inter-vertebral motion to investigate its links with IV-RoMmax and initial attainment rate. These results provide clues as to what may happen when kinematic or morphological changes are imposed through conservative treatment or surgery, both as local and regional effects. The apparent inter-dependency may assist in building rationales for treatments, and highlights the need to account for factors such as lordosis when conducting kinematic studies. If the results are re-affirmed by multivariate investigations in larger samples, future longitudinal studies are recommended to investigate the effect of interventions in low back pain populations, that have been informed by the relationships described in this study.

\section{Limitations}

The study's results are only representative of one young, healthy, male population and replication with larger and more extensive populations would be required to explore the relationships in wider age groups and in females. In light of this, any discussions relating to the investigation and management of wider LBP populations warrant careful consideration. Furthermore, it was also not possible to address the impact of loading on spinal behaviour, although every effort was made to standardise the population sample and study protocol for body mass index. In this research all measurements were made during weightbearing, and therefore the effect of muscle activity is also a consideration. A concurrent study conducted by our research group examines the relationships between lumbar paraspinal muscle activity and the kinematic and morphological variables described here [45]. Future studies may also wish to consider the use of dynamic stereo $\mathrm{x}$-ray imaging [15], especially if investigation of rotation in the transverse or coronal planes is required, where associated out of plane movements are more prominent.

\section{Conclusions}

IV-RoMmax and initial attainment rate measurements made using a QF weight-bearing sagittal plane protocol demonstrated acceptable reliability and agreement. Significant correlations were found between IV-RoMmax, IVRoMmax at different inter-vertebral levels, lordosis and initial attainment rate. The study demonstrated weak to moderate effects of these variables on IV-RoMmax. The potential prognostic and treatment effects of these relationships merit exploration with multivariate studies in larger samples, potentially leading to longitudinal investigations in back pain populations.

\section{Additional file}

Additional file 1: STROBE Statement-checklist of items that should be included in reports of observational studies (DOCX $40 \mathrm{~kb}$ )

\section{Abbreviations}

AECC: Anglo-European College of Chiropractic; BMI: body mass index; Cl: confidence interval; IBM SPSS: International Business Machines Corporation Statistical Package for the Social Sciences; ICC: intraclass correlation coefficient; IV-RoM: inter-vertebral range of motion; IV-RoMmax: maximum inter-vertebral range of motion; MRI: magnetic resonance imaging; $\mathrm{mSv}$ : millisievert; n: number; NRES: National Research Ethics Service; QF: quantitative fluoroscopy; SD: standard deviation; SEM: standard error of measurement.

\section{Competing interests}

The authors declare that they have no competing interests.

\section{Authors' contributions}

ADR served as project lead, performed the statistical analysis, conducted the image analysis and wrote the first draft. $A B$ operated the motion table. Both authors contributed to the study design, procedural protocols, data acquisition and the drafting of this paper. Both authors read and approved the final manuscript.

\section{Acknowledgements}

The study was funded by the EAC European Chiropractors Union Research Fund, and with contributions from the AECC Treatment-a-Month Club. We are also thankful for the assistance of Alex Breen, for measuring and analysing IV-RoMmax and initial attainment rate for the inter-observer study, and to Fiona Mellor for the image acquisitions. We are also grateful to lan Swain and Mihai

Dupac for their advice and suggestions and to Clive Osmond and Zoe

Sheppard for their statistical guidance.

Received: 5 November 2015 Accepted: 4 March 2016

Published online: 10 March 2016

\section{References}

1. Sahrmann SA. Movement Impairment Syndromes of the Lumbar Spine. In: Diagnosis and Treatment of Movement Impairment Syndromes. edn. St. Louis: Mosby, Inc; 2002. p. 51-119.

2. Iguchi T, Kanemura A, Kasahara K, Sato K, Kurihara A, Yoshiya S, Nishida, K, Miyamoto, H, Doita, M. Lumbar instability and clinical symptoms. Which is the more critical factor for symptoms: sagittal translation or segment angulation? J Spinal Disord Tech. 2004;17:284-90.

3. Kanemura A, Doita M, Kasahara K, Sumi M, Kurosaka M, Iguchi T. The influence of sagittal instability factors on clinical lumbar spinal symptoms. J Spinal Disord Tech. 2009;22(7):479-85. 
4. Spinelli BA, Wattananon P, Silfies S, Talaty M, Ebaugh D. Using kinematics and a dynamical systems approach to enhance understanding of clinically observed aberrant movement patterns. Man Ther. 2015;20:221-6.

5. Fritz JM, Cleland JA, Childs JD. Subgrouping Patients with Low Back Pain: Evolution of a Classification Approach to Physical Therapy. J Orthop Sports Phys Ther. 2007:37(6):290-302.

6. O'Sullivan P. Diagnosis and classificiation of chronic low back pain disorders: Maladaptive movement and motor control impairments as underlying mechanism. Man Ther. 2005;10:242-55.

7. Steiger F, Becker H-J, Standaert CJ, Nalague F, Vader J-P, Porchet F, Mannion AF. Surgery in lumbar degenerative spondylolisthesis: indications, outcomes and complications. A systematic review. Eur Spine J. 2014;23:945-73.

8. Fritz JM, Erhard RE, Hagen BF. Segmental instability of the lumbar spine. Phys Ther. 1998;78:889-96

9. Panjabi MM. The stabilising system of the spine - Part 1: Function, dysfunction, adaptation and enhancement. J Spinal Disord. 1992;5(4):383-9.

10. Panjabi MM. The stabilising system of the spine - Part 2: Neutral zone and instability hypothesis. J Spinal Disord. 1992;5(4):390-7.

11. Mellor FE, Thomas $\mathrm{P}$, Thompson $\mathrm{P}$, Breen AC. Proportional lumbar spine intervertebral motion patterns: A comparison of patients with chronic non-specific low back pain and healthy controls. Eur Spine J. 2014;23(10):2059-67.

12. Li G, Wang S, Passias P, Xia Q, Li G, Wood K. Segmental in vivo vertebral motion during function human lumbar spine activities. Eur Spine J. 2009;18: 1013-21.

13. Teyhen DS, Flynn TW, Bovik AC, Abraham LD. A new technique for digital fluoroscopic video assessment of sagittal plane lumbar spine motion. Spine. 2005;30(14):E406-13.

14. Yeager MS, Cook DJ, Cheng BC. Reliability of computer-assisted lumbar intervertebral measurement using a novel vertebral motion analysis system. Spine J. 2014;14(2):274-81.

15. Aiyangar AK, Zheng L, Tashman S, Anderst WJ, Zhang X. Capturing ThreeDimensional In Vivo Lumbar Intervertebral Joint Kinematics Using Dynamic Stereo-X-Ray Imaging. J Biomech Eng. 2014;136:011004-011001-9.

16. Pearcy MJ. Stereoradiography of lumbar spine motion. Acta Orthop Scand. 1985;56(212(suppl)):1-45.

17. Ellingson AM, Nuckey DJ. Altered helical axis patterns of the lumbar spine indicate increased instablity with disc degeneration. J Biomech. 2015;48: $361-9$

18. Harvey SB, Hukins DW. Measurement of lumbar spinal flexion-extension kinematics from lateral radiographs: simulation of the effects of out-of-plane movement and errors in reference point placement. Med Eng Phys. 1998;20: 403-9.

19. Harvey RM, Goodsitt J, Khayatzadeh S, Muriuki M, Potluri T, Voronov LI, Lomasney LM, Patwardhan AG. Three-Dimensional Computed TomographyBased Specimen-Specific Kinematic Model for Ex Vivo Assessment of Lumbar Neuroforaminal Space. Spine. 2015;40(14):E814-22.

20. Breen A, Muggleton J, Mellor F. An objective spinal motion imaging assessment (OSMIA): reliability, accuracy and exposure data. BMC Musculoskelet Disord. 2006;7(1):1-10.

21. Breen AC, Teyhan DS, Mellor FE, Breen AC, Wong KWN, Deitz A. Measurement of InterVertebral Motion Using Quantitative Fluoroscopy: Report of an International Forum and Proposal for Use in the Assessment of Degenerative Disc Disease in the Lumbar Spine. Adv Orthop. 2012;2012:802350.

22. Wu M, Wang S, Driscoll SJ, Cha TD, Wood KB, Li G. Dynamic motion characteristics of the lower lumbar spine: implication to lumbar pathology and surgical treatment. Eur Spine J. 2014;23:2350-8.

23. Xia Q, Wang S, Passias PG, Kozanek M, Li G, Grottkau BE, Wood KB, Li G. In vivo range of motion of the lumbar spinous processes. Eur Spine J. 2009;18: 1355-62.

24. Kanayama M, Abumi K, Kaneda K, Tadano S, Ukai T. Phase Lag of the Intersegmental Motion in Flexion-Extension of the Lumbar and Lumbosacral Spine: An In Vivo Study. Spine. 1996:21(12):1416-22.

25. Been E, Kalichman L. Lumbar lordosis. Spine J. 2014;14(1):87-97.

26. Pavlova AV, Meakin JR, Cooper K, Barr RJ, Aspden RM. The lumbar spine has an intrinsic shape specific to each individual that remains a characteristic throughout flexion and extension. Eur Spine J. 2014:23 Suppl 1:S26-32.

27. Pearson AM, Spratt KF, Genuario J, McGough W, Kosman K, Lurie J, Sengupta DK. Precision of Lumbar Intervertebral Measurements. Spine. 2011; 36(7):572-80.

28. Teyhen DS, Flynn TW, Childs JD, Kuklo TR, Rosner MK, Polly DW, Abraham LD. Fluoroscopic Video to Identify Aberrant Lumbar Motion. Spine. 2007;32(7):E220-9.
29. Wong KWN, Leong JCY, Chan M-K, Lu WW. The flexion-extension profile of lumbar spine in 100 healthy volunteers. Spine. 2004;29(15):1636-41.

30. Breen AC, Teyhen DS, Mellor FE, Breen AC, Wong K, Deitz A. Measurement of inter-vertebral motion using quantitative fluoroscopy: Report of an international forum and proposal for use in the assessment of degenerative disc disease in the lumbar spine. Advances in Orthopaedics. 2012;2012:1-10.

31. Mellor F, Muggleton JM, Bagust J, Mason W, Thomas PW, Breen AC. Midlumbar lateral flexion stability measured in healthy volunteers by in-vivo fluoroscopy. Spine. 2009;34(22):E811-7.

32. Breen AC, Dupac M, Osborne N. Attainment rate as a surrogate indicator of the intervertebral neutral zone length in lateral bending: An in vitro proof of concept study. Chiropr Man Therap. 2015;23:28.

33. Julious SA. Sample size of 12 per group rule of thumb for a pilot study. Pharm Stat. 2005;4:287-91.

34. Dvorak J, Panjabi MM, Chang DG, Theiler R, Grob D. Functional radiographic diagnosis of the lumbar spine: flexion-extension and lateral bending. Spine. 1991;16(5):562-71.

35. de Vet $\mathrm{HCW}$, Terwee $C B$, Knol DL, Bouter $L M$. When to use agreement versus reliability measures. J Clin Epidemiol. 2006;59(10):1033-9.

36. Frobin F, Brinckmann P, Lievseth G, Biggemann M, Reikeras O. Precision measurement of segmental motion from flexion-extension radiographs of the lumbar spine. Clin Biomechanics. 1996:11(8):457-65.

37. Von Elm E, Altman DG, Egger M, Pocock SJ, Gotzsche PC, Vandenbroucke JP, for the STROBE Initiative. The Strengthening the Reporting of Observational Studies in Epidemiology (STROBE) statement: quidelines for reporting observational studies. J Clin Epidemiol. 2008;61:344-9.

38. Shrout PE. Measurement reliability and agreement in psychiatry. Stat Methods Med Res. 1998;7(3):301-17.

39. Lee S, Wong K, Chan M, Yeung H, Chiu J, Leong J. Development and Validation of a New Technique for Assessing Lumbar Spine Motion. Spine. 2002;27(8): E215-20.

40. Aspden RM. The Spine as an Arch. A new mathematical model. Spine. 1989; 14(3):266-74.

41. Doulgeris JJ, Aghayev K, Gonzalez-Blohm SA, Lee III WE, Vrionis FD. Biomechanical comparison of an interspinous fusion device and bilateral pedical screw system as additional fixation for lateral lumbar interbody fusion. Clin Biomechanics. 2015:30:205-10

42. Barrey C, Darnis A. Current strategies for the restoration of adequate lordosis during lumbar fusion. World J Orthop. 2015:6(1):117-26.

43. Mehta VA, Amin A, Omeis I, Gokaslan ZL, Gottfried ON. Implications of Spinopelvic Alignment for the Spine Surgeon. Neurosurgery. 2012;70(3):707-21.

44. Roussouly P, Pinheiro-Franco $\mathrm{JL}$. Biomechanical analysis of the spino-pelvic organization and adaptation in pathology. Eur Spine J. 2011;20 Suppl 5: S609-18.

45. du Rose A, Breen A. Relationships between Paraspinal Muscle Activity and Lumbar Inter-Vertebral Range of Motion. Healthcare. 2016:4(1):Article 4.

\section{Submit your next manuscript to BioMed Central and we will help you at every step:}

- We accept pre-submission inquiries

- Our selector tool helps you to find the most relevant journal

- We provide round the clock customer support

- Convenient online submission

- Thorough peer review

- Inclusion in PubMed and all major indexing services

- Maximum visibility for your research

Submit your manuscript at www.biomedcentral.com/submit 